\title{
DIAGNOSIS OF CANINE ECHINOCOCCOSIS: COMPARISON OF COPROANTIGEN DETECTION WITH NECROPSY IN STRAY DOGS AND RED FOXES FROM NORTHERN JORDAN
}

\author{
EL-SHEHABI F.S.*, KAMHAWI S.A.*, SCHANTZ P.M.**, CRAIG P.S.*** \& ABDEL-HAFEZ S.K.*
}

Summary :

The sandwich enzyme linked immunosorbent assay (ELISA) was used as a diagnostic test for Echinococcus granulosus infection by detecting coproantigens in 94 stray dogs Canis familiaris and eight red foxes (Vulpes vulpes) from northern Jordan. The results were analyzed in relation to actual helminth infection as revealed by necropsy. The infection rate of dogs with $E$. granulosus was $13.8 \%$ with a worm load ranging between $3->10,000$ per infected dog. In contrast, eight of 13 E. granulosus infected dogs were coproantigen positive (overall sensitivity $61.5 \%$ ). The sensitivity increased to $87.5 \%$ and $100 \%$ in dogs harboring $>20$ and $>100$ worms/dog, respectively. The specificity of coproantigen-ELISA was $91 \%$. The greatest cross-reactivity was found in dogs infected with Dipylidium caninum. The positive and negative predictive values for the coproantigen-ELISA test were $50 \%$ and $94.2 \%$, respectively. Thus, a coproantigen negative dog is most probably truly negative for $E$. granulosus. In contrast, a coproantigen positive dog may not be truly positive for E. granulosus, except if it has a high worm burden of $>100$ worms/animal.

KEY WORDS : Echinococcus granulosus, canine echinococcosis, coproantigens, Jordan.

\section{INTRODUCTION}

U nilocular hydatidosis or cystic echinococcosis (CE) is a cosmopolitan cyclozoonotic disease caused by the taeniid cestode Echinococcus granulosus and is one of the major parasitic diseases of public health importance (Mattosian et al., 1977; Schantz \& Kramer, 1995; Schantz et al., 1995). The disease is endemic or highly endemic in Middle Eastern countries including Lebanon, Syria, Palestinian Authority, Israel, and Jordan (See review by AbdelHafez \& Kamhawi, 1997). The stability of CE in Jordan

\footnotetext{
* Department of Biological Sciences, Yarmouk University, Irbid, Jordan.

** Division of Parasitic Diseases, National Center for Infectious Diseases, Centers of Disease Control and Prevention, Atlanta, Georgia 30341, USA

*** Department of Biological Sciences, University of Salford, Salford, M5 4WT, UK

Correspondence: Sami K. Abdel-Hafez.

Fax: +962 27246575 - e-mail: skhafez@yu.edu.jo
}

Résumé : DiAGNOSTIC DE L'EChINOCOCCOSE CANINE : COMPARAISON ENTRE LA DÉTECTION DE COPROANTIGÈNES ET LA NÉCROPSIE CHEZ DES CHIENS ERRANTS ET DES RENARDS ROUGES DU NORD DE LA JORDANIE

La méthode ELISA de type sandwich a été utilisée pour le diagnostic de l'infection à Echinococcus granulosus par la détection de coproantigènes chez 94 chiens errants et huit renards rouges Nulpes vulpes/ provenant du nord de la Jordanie. Les résultats ont été comparés avec ceux obtenus par nécropsie. Chez les chiens, le taux d'infection par E. granulosus était de 13,8\% avec une charge parasitaire de trois à plus de 10000 vers par animal. En revanche, sur les 13 chiens infectés, huit étaient coproantigène positifs (sensibilité de 61,5\%). La sensibilité croît à $87,5 \%$ et $100 \%$ chez les chiens porteurs respectivement de plus de 20 et de plus de 100 vers. La spécificité du test ELISAcoproantigène était de $91 \%$. La réaction croisée la plus importante a été observée chez les chiens porteurs de Dipylidium caninum. Les valeurs prédictives positives et négatives pour le test ELISA-coproantigène étaient respectivement de 50 et $94,2 \%$. Ainsi, un chien coproantigène négatif est très probablement non infecté par E. granulosus. A contrario, un chien coproantigène positif n'est peut-être pas réellement infecté par E. granulosus, sauf si sa charge parasitaire est élevée, supérieure à 100 vers.

MOTS CLÉS : Echinococcus granulosus, échinococcose canine, coproantigène, Jordanie.

is multi-factorial as pertaining to improper slaughtering and human practices as well as to the abundance of stray dogs (Abdel-Hafez et al., 1986; Abdel-Hafez \& Kamhawi, 1997).

The epidemiology of $\mathrm{CE}$ requires the consideration of three host components: the ungulate herbivore intermediate hosts, humans as accidental hosts and dogs as definitive hosts. Determination of prevalence and incidence in these hosts should precede any planning of a control program. Direct identification of hydatid cysts in various organs of slaughtered intermediate hosts can determine the level of endemicity of the disease in a given area (Gemmell, 1997). Both serological and imaging techniques are used to diagnose human $\mathrm{CE}$ infections and to determine the prevalence and incidence in endemic countries (Schantz \& Kramer, 1995). Direct and indirect methods can determine the prevalence of canine echinococcosis. Direct methods rely on the examination of purgative samples or contents of small intestine following necropsy as well as of fecal specimens to identify whole worms, proglottids and/or eggs (Eckert et al., 1984; Allan et al., 
1992; Craig, 1993). These methods not only are timeconsuming, but also suffer from low sensitivity and specificity (Craig, 1997). Eggs are not released during the pre-patent period and their release is irregular during patency (Nonaka et al., 1996). Morphological similarities among eggs of all the taeniid species that may infect dogs simultaneously limit the specificity of direct methods. In addition, these tests are quite hazardous to both animals and examiners. Indirect methods are based on the identification of copro-DNA, anti-adult worms antibodies in the serum and feces as well as by coproantigens detection. Serodiagnosis is accompanied with false negative results at the commencement of infection and false positive ones due to cross reactivity with other helminth infections (Jenkins \& Rickard, 1985 and 1986; Gasser et al., 1988 and 1993). The sandwich enzyme linked immunosorbent assay (ELISA) has recently been applied for diagnosis of E. granulosus and E. multilocularis in canines through the detection of coproantigens (Allan et al., 1992; Deplazes et al., 1992 and 1994; Craig et al., 1995; Nonaka et al., 1996; Malgor et al., 1997; Ahmad \& Nizami, 1998). The coproantigen test has the advantage of early detection of the infection during prepatency, in 4-10 days post-infection (Deplazes et al., 1992). Moreover, positive results indicate current infection because coproantigens are derived from adult worms and would disappear as soon as the parasites are eliminated.

In this study, the E. granulosus coproantigen test was used to assess the sensitivity, specificity and the positive and negative predictive values of this test under field conditions in stray dogs and red foxes from northern Jordan.

\section{MATERIALS AND METHODS}

$\mathrm{N}$ inety four stray dogs (Canis familiaris Linnaeus, 1758) and eight red foxes (Vulpes vulpes Linnaeus (1758)) from Irbid and Mafraq Governorates, northern Jordan were shot in the field between June, 1994-July, 1995.

The necropsy of the animals was carried out in the field as described by El-Shihabi et al. (1999). Briefly, an abdominal cut was made in each animal and the intestine was tied from the pyloric and anal ends and collected in a bag. Bags were stored in an icebox and carried to the laboratory within three hours. The carcasses were burned in the field to ensure no contamination of the environment. In the laboratory, each intestine was divided into four pieces of equal length. Each piece was cut longitudinally and soaked in $0.15 \mathrm{M}$ phosphate buffer saline (PBS, pH 7.2) for five minutes. The mucosal lining was gently scraped with a spatula into clean glass dishes and the collected intestinal contents were allowed to settle in $1,000 \mathrm{ml}$ conical Nalgene graduates (Nalge Company, Rochester, USA). Following several washes with PBS, aliquots were examined under a dissecting microscope. The intestinal helminth parasites were identified as described earlier by El-Shihabi et al. (1999).

\section{E. GRANULOSUS ADULT WORM CRUDE SOMATIC ANTIGEN EXTRACT}

E. granulosus adult worm crude somatic antigen (EgACSA) extract was prepared as described earlier (Allan et al., 1992). Briefly, about 500-600 adult E. granulosus worms were isolated from the small intestines of infected animals. They were washed three times with $0.15 \mathrm{M}$ Streptomycin containing phosphate buffer saline (PBS, $\mathrm{pH}$ 7.2) for 30 minutes. Thereafter, they were frozen at $-20^{\circ} \mathrm{C}$, thawed twice and homogenized using $2 \mathrm{ml}$ capacity glass homogenizer in ice bucket for five minutes. Finally, the homogenate was centrifuged at $1,500 \mathrm{~g}$ for 20 minutes at $4^{\circ} \mathrm{C}$ and the protein content of the supernatant was determined by Bradford method (Bradford, 1976).

\section{COPROANTIGEN PREPARATION}

Fresh fecal materials were collected from each dog and fox and mixed in 1:1 w/v ratio with $0.15 \mathrm{M}$ PBS ( $\mathrm{pH} 7.2$ ) containing $0.3 \%$ Tween 20 . The mixture was shaken vigorously using a Vortex shaker and then centrifuged at 2,000 $\mathrm{g}$ for 30 minutes at $4^{\circ} \mathrm{C}$. The supernatants were frozen at $-20^{\circ} \mathrm{C}$ and stored until further use.

\section{COPROANTIGEN-ELISA}

Hyperimmune rabbit anti EgACSA antiserum was prepared as described previously (Allan \& Craig, 1989). The IgG fraction was purified using protein $\mathrm{A}$ as a ligand in affinity chromatography of protein A-Sepharose CL-4B (Pharmacia Fine Chemicals, Uppsala, Sweden). Conjugation of the IgG fraction with horseradish peroxidase type VI enzyme (Sigma, USA) and the IgG capture ELISA were carried out as described previously (Allan and Craig, 1989) with modification. Briefly, wells of microtiter plates (Greiner F ELISA plates, Frickenhausen, Germany) were coated overnight with $100 \mu \mathrm{l}$ of rabbit anti EgACSA IgG at a dilution of 1:800 in $0.05 \mathrm{M}$ carbonate buffer, $\mathrm{pH} 9.6$ at $4^{\circ} \mathrm{C}$ using rocking plate shaker (Denley, England). The wells were washed three times with $0.1 \%$ Tween 20 in 0.15 M PBS, pH 7.2 and blocked with $4 \%$ bovine serum albumin (fraction V, PARK, UK) or $12 \%$ skimmed milk (Regilait instant dried skimmed milk, France) in 0.15 M PBS, $\mathrm{pH} 7.2$ for one hour at room temperature (RT). Following washing the wells three times, the fecal supernatants were mixed individually with heat inactivated 


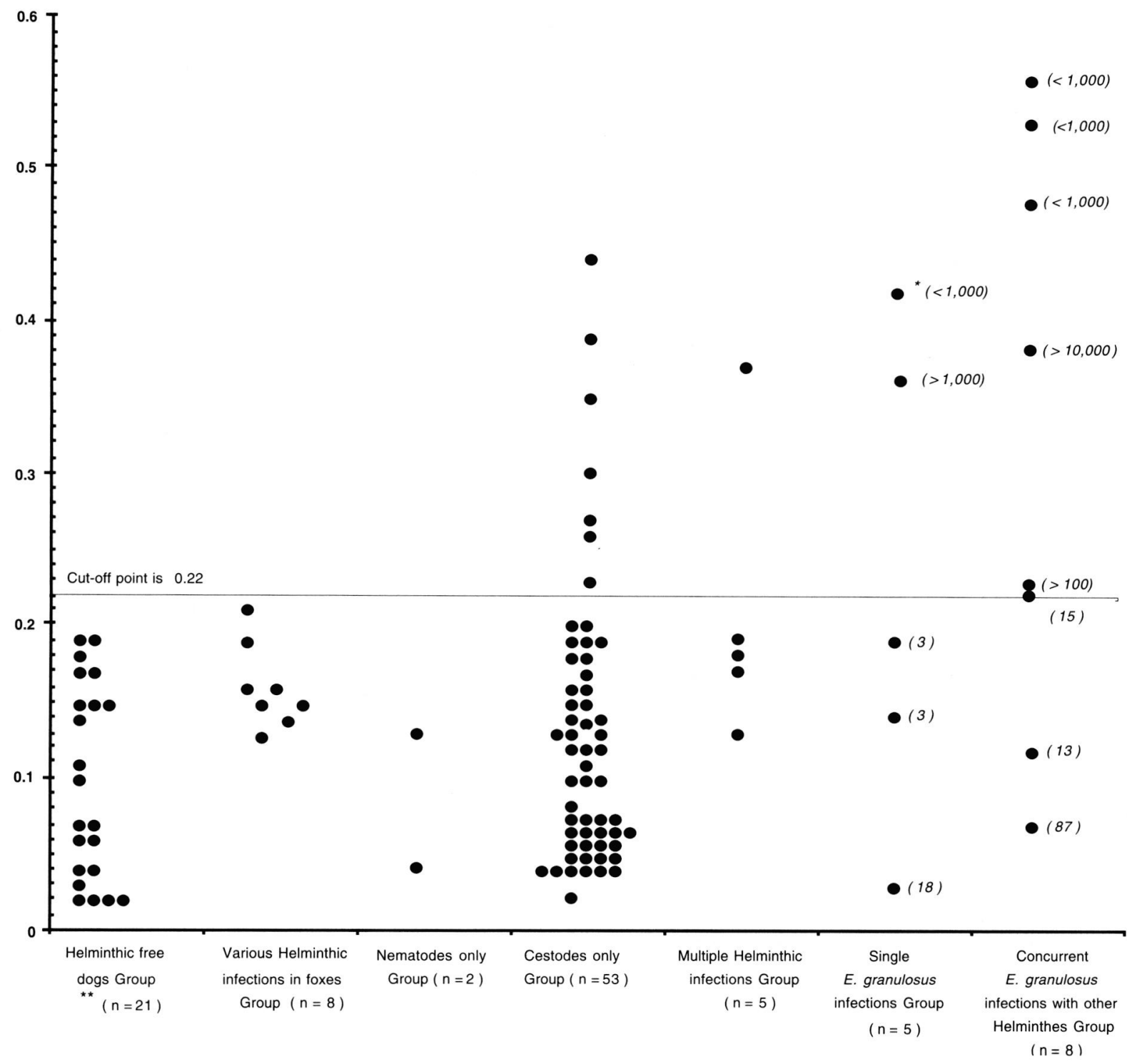

Fig. 1. - Detection of E. gramulosus coproantigens in dogs and foxes by IgG capture ELISA. The cut-off point value (-) was determined by calculating the mean optical density (O.D.) value at $\lambda 490 \mathrm{~nm}$ for 21 fecal samples of helminth free dogs $+3 \mathrm{~S}$. D.

* Number in parenthesis indicates the worm burden of E. gramulosus in infected dogs as determined by necropsy.

** Number in parenthesis denotes number of animals examined in each group.

fetal calf serum (FCS) at 1:1 $\mathrm{v} / \mathrm{v}$ ratio (Sigma, USA), and $100 \mu \mathrm{l}$ of each sample was added per well and incubated for one hour at RT. After three washings, $100 \mu \mathrm{l}$ of horseradish peroxidase (HRP) conjugated with anti EgACSA IgG at a dilution of 1:200 was added and incubated for one hour. After three washings, $100 \mu \mathrm{l}$ of substrate solution consists of $\mathrm{H}_{2} \mathrm{O}_{2}$ in $0.1 \mathrm{M}$ citrate buffer, $\mathrm{pH} 4.5$ containing ortho-phenyldiamine (OPD) chromogen (Sigma, USA) was incubated for 30 minutes at RT in dark. Finally, the optical density of each well was read at a wavelength of $490 \mathrm{~nm}$ using Micro-ELISA auto-reader (Dynatech, Virginia, USA). Positive control wells contained $5 \mu \mathrm{g} / \mathrm{ml}$ EgACSA ins- tead of fecal sample. Negative control wells contained pooled fecal materials from helminth free dogs. External marginal wells of each micro-titer plate were excluded. The cut-off point was calculated by measuring the mean optical density (OD) at $490 \mathrm{~nm}$ of helminth free dog fecal samples $($ no $=21)+3 \mathrm{SD}$. All fecal samples were tested in triplicate.

\section{EVALUATION OF COPROANTIGEN-ELISA TEST}

To assess the efficacy of the coproantigen ELISA, the sensitivity, specificity, positive predictive and negative predictive values of the test were determined using necropsy data as a golden standard (Schantz, 1997). 


\section{RESULTS}

\section{NECROPSY DATA}

- Vable I shows that 13 of $94(13.8 \%)$ stray dogs were infected with $E$. granulosus either as single or concurrent infections with other helminthic species. Single infection with $E$. granulosus accounted for $5.3 \%$ of the dogs $(38.5 \%$ of infected dogs). None of eight foxes was found infected with E. granulosus. Worm burden with E. gramulosus ranged from 3-> 10,000 worms per dog, with $46.2 \%$ of infected dogs having a worm burden of $<100$ worms/animal (Table II). All eight foxes and $77.7 \%$ of the dogs were infected with at least one intestinal helminth species (Table III). Moreover, single or concurrent cestode infections accounted for $71 / 73(97.3 \%)$ of the infected dogs and six out of the eight foxes. The most predominant helminth species encountered in stray dogs was Dipylidium caninum alone or in combination with other Dipylidids and/or other cestodes. The infection rate

\begin{tabular}{|c|c|c|}
\hline Infection mode & $\begin{array}{l}\text { No. of } \\
\text { infected } \\
\text { dogs }\end{array}$ & $\%$ \\
\hline Single E. granulosus infection & 5 & 5.3 \\
\hline \multicolumn{3}{|l|}{ Concurrent infection with: } \\
\hline Taenia spp. (a) & 2 & 2.1 \\
\hline Dipylidids $^{(\mathrm{b})}$ & 1 & 1.1 \\
\hline Taenia spp. ${ }^{(a)}$ and Dipylidids ${ }^{(b)}$ & 2 & 2.1 \\
\hline Dipylidids $^{(\mathrm{b})}$ and Nematodes ${ }^{(\mathrm{c})}$ & 1 & 1.1 \\
\hline Taenia spp. ${ }^{(\mathrm{a})}$, Dipylidids ${ }^{(\mathrm{b})}$ and Nematodes ${ }^{(\mathrm{c})}$ & 1 & 1.1 \\
\hline Taenia spp. ${ }^{(a)}$, Dipylidids ${ }^{(\mathrm{b})}$ and Mesocestoides sp. & 1 & 1.1 \\
\hline Total infection & 13 & 13.8 \\
\hline
\end{tabular}

(a) Taenia spp. included T. pisiformis, T. taeniaeformis and other unidentified Taenia species.

(b) Dipylidids included Dipylidium caninum, Diplopylidium sp. and Joyeuxiella sp.

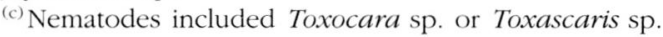

Table I. - Rates of dog infection with E. granulosus either alone (single infection) or concurrent infections with other helminths in 94 dogs from northern Jordan.

\begin{tabular}{llcc}
\hline & \multicolumn{2}{c}{$\begin{array}{c}\text { No. and percentage } \\
\text { of infected dogs }\end{array}$} \\
\cline { 2 - 4 } Worm burden of E. granulosus & \multicolumn{2}{c}{ No. } & $\%$ \\
\hline$<20$ & 5 & 38.5 \\
$20-<100$ & 1 & 7.7 \\
$100-<500$ & 1 & 7.7 \\
$500-<1,000$ & 4 & 30.7 \\
& $1,000-<5,000$ & 1 & 7.7 \\
\hline \multirow{2}{*}{ Total } & $>10,000$ & 1 & 7.7 \\
\hline
\end{tabular}

Table II. - Worm burden of E. granulosus in infected dogs from northern Jordan.

\begin{tabular}{|c|c|c|c|c|c|c|}
\hline \multirow[b]{3}{*}{ Type of infection ${ }^{1}$} & \multicolumn{4}{|c|}{ Dogs } & \multicolumn{2}{|c|}{ Foxes $^{2}$} \\
\hline & \multicolumn{2}{|c|}{ Necropsy } & \multicolumn{2}{|c|}{$\begin{array}{l}\text { Copro- } \\
\text { ELISA }\end{array}$} & \multicolumn{2}{|c|}{ Necropsy } \\
\hline & No. & $\%$ & No. & $\%$ & No. & $\%$ \\
\hline Helminth free & 21 & 22.3 & 0 & 0.0 & 0 & 0.0 \\
\hline E. granulosus alone & 5 & 5.3 & 2 & 2.1 & 0 & 0.0 \\
\hline E. granulosus \& other ces. & 6 & 6.4 & 5 & 5.3 & 0 & 0.0 \\
\hline E. granulosus, other ces. \& nem. & 2 & 2.1 & 1 & 1.1 & 0 & 0.0 \\
\hline Other ces. & 53 & 56.4 & 7 & 7.4 & 3 & 37.5 \\
\hline Cestodes, nem. \& /or acantho. & 5 & 5.3 & 1 & 1.1 & 3 & 37.5 \\
\hline Other nem. \& /or acantho. & 2 & 2.1 & 0 & 0.0 & 2 & 25.0 \\
\hline Total infection & 94 & 100.0 & 16 & 17.0 & 8 & 100.0 \\
\hline
\end{tabular}

${ }^{1}$ Abbreviations: ces., cestodes; nem., nematodes; acanth., acanthocephalans.

${ }^{2}$ Faecal specimens of all foxes were copro-ELISA negative.

Table III. - Intestinal helminth fauna and infection rates in dogs and foxes from northern Jordan. Necropsy data were used to assess the diagnosis of E. granulosus coproantigens by capture ELISA.

with this species was $51.1 \%$ (48 out of total 94 necropsied dogs) and $65.8 \%$ of the total number of dogs infected with helminths. All foxes were found infected with one or more species of cestodes, nematodes and/or acanthocephalans but never with either E. granulosus or Taenia species (Table III). Five of the foxes were found infected with Dipylidids, particularly Diplopylidium and Joyeuxiella species. Three foxes were infected concurrently with Macracanthorbynchus acanthocephalan and other cestodes and/or nematodes.

\section{SENSITIVITY, SPECIFICITY, POSITIVE AND NEGATIVE PREDICTIVE VALUES OF COPROANTIGEN-ELISA}

Table III compares the coproantigen-ELISA results with necropsy data of dogs and foxes. While none of the fox fecal samples were coproantigen positive, 16 of 94 (17.0\%) of the dog fecal samples were coproantigen positive. Eight of 13 E. granulosus positive dogs as revealed by necropsy were also coproantigen positive. In contrast, out of 89 canines (dogs and foxes) which were negative for E. granulosus infections by necropsy, eight were positive in the coproantigen assay. In this way, the sensitivity of coproantigen-ELISA test for 94 dogs and eight foxes was $61.5 \%$, while the specificity of this test was $91.0 \%$ (Table IV). The positive predictive value of this test was $50 \%$ while the negative predictive value was as high as $94.2 \%$. All of the five false-coproantigen negative samples were for dogs harboring an E. granulosus worm burden of $<100$ worms (Fig. 1). Moreover, seven out of eight dogs harboring $>20$ E. granulosus worms were coproantigen positive. This increases the sensitivity values of the test for dogs with E. granulosus burden of $>20$ and $>100$ worms 
O. D. $490 \mathrm{~nm}$

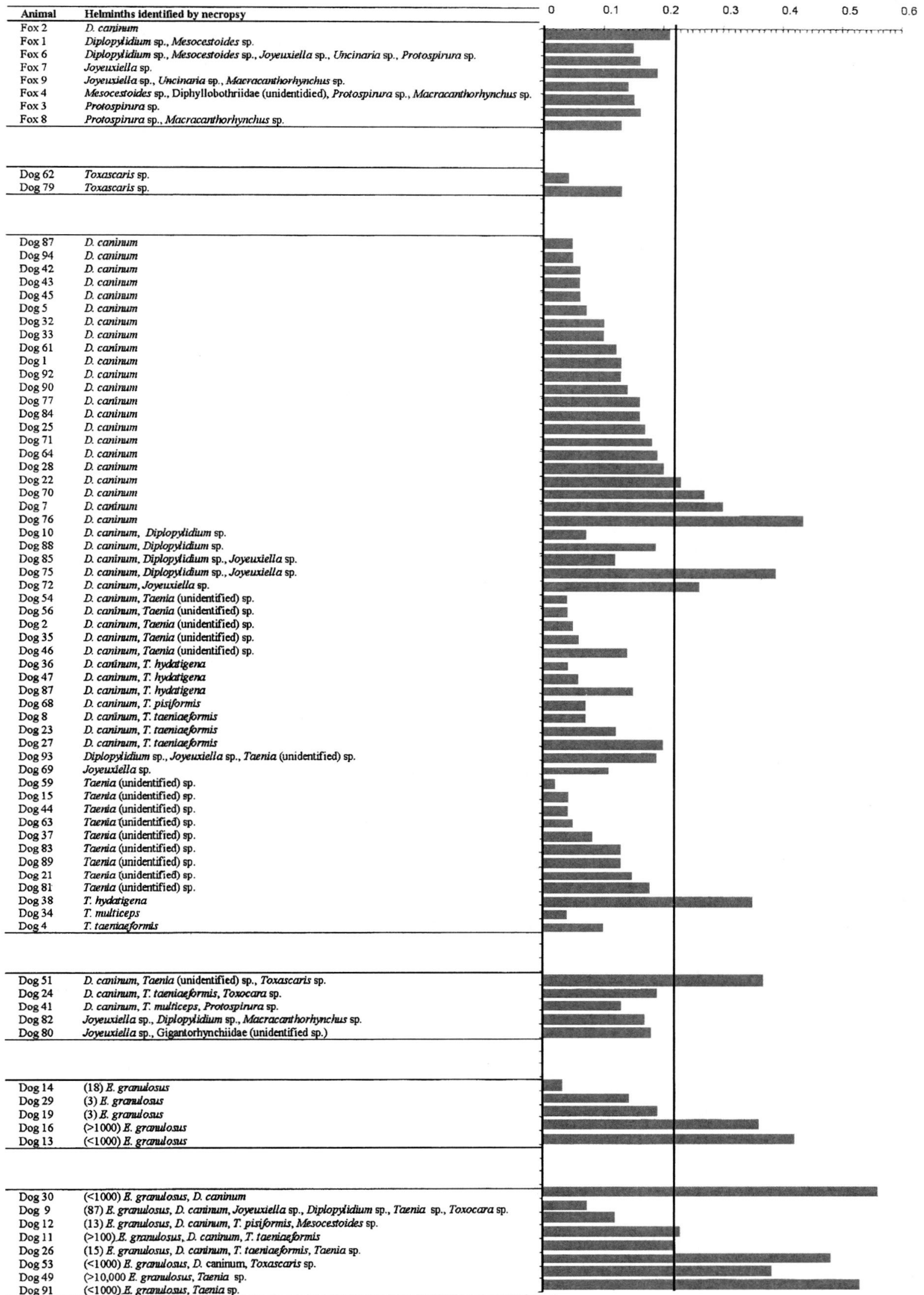

Fig. 2. - Detection of E. granulosus coproantigens by IgG capture ELISA in 81 fecal samples from 73 stray dogs and eight red foxes, all of which were infected with at least one species of intestinal belminths. The cut-off point value (-) was calculated as in Figure 1. 


\begin{tabular}{lcc}
\hline \multicolumn{1}{c}{ Parameter } & Coproantigen-ELISA & $\mathbf{\%}$ \\
\hline Sensitivity $^{1}$ & $8 / 13$ & 61.5 \\
Specificity $^{2}$ & $81 / 89$ & 91.0 \\
Positive predictive value $^{3}$ & $8 / 16$ & 50.0 \\
Negative predictive value $^{4}$ & $81 / 86$ & 94.2 \\
\hline
\end{tabular}

${ }^{1}$ Sensitivity of coproantigen-ELISA was calculated as \% E. granulosus copro-positive animals/all positives by necropsy.

${ }^{2}$ Specificity of coproantigen-ELISA was calculated as \% E. granulosus copro-negative animals/all negatives by necropsy.

${ }^{3}$ Positive predictive value of coproantigen-ELISA was calculated as $\%$ E. granulosus positive animals by both necropsy and coproantigen-ELISA/all copro-positives by coproantigen-ELISA alone.

${ }^{4}$ Negative predictive value of coproantigen-ELISA was calculated as $\%$ E. granulosus negative animals by both necropsy and coproantigen-ELISA/all copro-negatives by coproantigen-ELISA alone.

Table IV. - Sensitivity, specificity, positive and negative predictive values of coproantigen-ELISA test for E. gramulosus detection in 94 stray dogs and eight red foxes from northern Jordan.

to $87.5 \%$ and $100.0 \%$, respectively. Figure 2 depicts the ELISA OD readings for coproantigens in the fecal samples of all dogs and foxes infected with intestinal helminths as compared with the necropsy data. Evidently, higher OD values were mostly seen in dogs infected with high E. granulosus burdens whether singly or concurrently with other helminth parasites. Out of the eight dog fecal samples that were false coproantigen positive, six were for dogs infected with D. caninum alone or with other Dipylidid species (i.e. Joyeuxiella and/or Diplopylidium species). One of the other two samples was infected with Taenia sp. and the other with both D. caninum and Taenia spp. (Fig. 2). In this way, out of 48 dogs which were $D$. caninum positive as revealed by necropsy, $41(85.4 \%)$ were coproantigen negative.

\section{DISCUSSION}

T n the present study, the IgG capture ELISA for the detection of coproantigens was used in conjunction with necropsy to determine the infection rate of E. gramulosus and other intestinal helminths in stray dogs and red foxes from northern Jordan. The infection rate with E. granulosus as determined by necropsy was $13.8 \%$. This conforms with our earlier report (ElShehabi et al., 1999), but was lower than what had been reported over 15 years ago in which $19.6 \%$ of stray dogs from Irbid Governorate were found infected (Ajlouni et al., 1984).

The sensitivity of coproantigens ELISA was found to be highly dependent on the E. granulosus worm burden. The overall sensitivity of the test was relatively low at $61.5 \%$ regardless of the worm load. However, the sensitivity reached as high as $87.5 \%$ and $100.0 \%$ for dogs harboring $>20$ and $>100$ worms/dog, respectively. It is this category of animals, which is most important epidemiologically as a source of livestock and human infection. Seven out of $13(53.8 \%)$ E. granulosus infected dogs had a worm burden of $>100$ worms/dog (Table II). Thus, the test is quite useful to monitor dog infection rates in surveillance and control program. It is simple, safe, cheap and less time-consuming than the other standard techniques that determine canine echinococcosis by necropsy or purgation with arecoline hydrobromide.

The positive predictive value of the test, as calculated here, appears to be quite low (Table IV) and denotes a reflection of the detectability level of the worm load. Lower E. granulosus infections (i.e. $<100$ worms/animal) yielded mostly negative coproantigen-ELISA results. The positive predictive value increased significantly with higher worm burdens. The detectable worm load by coproantigens-ELISA has influenced the positive predictive value of the test as only eight of total 16 coproantigen positive dogs were actually E. granulosus infected animals. Seven out of these eight animals had a worm burden $>100$ worms/dog. Thus, one can not rely on coproantigen-ELISA alone to diagnose low worm burden of E. gramulosus in dogs. In contrast, the negative predictive value was high (Table IV). Thus, a negative result confirms that a dog is either truly noninfected or harbors a very low worm burden infection, both conditions are epidemiologically not significant. The specificity of this test was high (91.0\%) and is comparable to what has been reported earlier (Allan et al., 1992; Deplazes et al., 1992; Craig et al., 1995).

In the present investigation, most of the cross reactivity was noted in dogs infected with $D$. caninum alone or with other Dipylidid worms. This contrasts earlier observations in which most false coproantigens-ELISA positive samples were seen in Taenia bydatigena infections (Allan et al., 1992; Deplazes et al., 1992; Molgar et al., 1997) Here, one of the eight false coproantigens positive samples was for a dog infected with $T$. bydatigena alone. Indeed, T. hydatigena infection was lower than D. caninum in the present series. This reflects the strayhood of the dogs in contrast to home owned dogs that are routinely dosed for fleas and other ectoparasites. Thus, the consideration of coproantigens as being genus-specific (Craig et al., 1995) must be re-examined. Apparently, some somatic antigens may be shared between Dipylidid and Taeniid worms including E. granulosus. The use of excretory/secretory (E/S) antigens instead of adult somatic crude antigens to hyperimmunize rabbit for the preparation of reagents to be used in coproantigens-ELISA may result in more genusspecific antibodies and diminish the cross-reactivity between different genera of cestodes (Deplazes et al., 1992). However, the true cross-reactivity between D. caninum and E. granulosus can only be proven by 
experimental infection studies with the two-helminth species. It should be pointed out that only $14.6 \%$ of 48 D. caninum infected dogs were coproantigen positive. One can not rule out that such dogs might have had recent E. gramulosus infection that had been cleared out. Alternatively, a very small worm load of E. granulosus might have been missed during necropsy of some of these dogs and thus resulted in coproantigen positivity.

The ultimate conclusion of this study is that coproantigen-ELISA is a suitable test that can be used in epidemiological surveys. Its sensitivity is very high in dogs harboring $>20$ worms/animal and is absolute in those with $>100$ worm load

Currently, this test has been adopted as a routine technique to investigate canine echinococcosis prevalence in various parts of the country.

\section{ACKNOWLEDGEMENTS}

The authors wish to thank the technical assistance Mr. J. Hawari. This work received financial support from NIAID-NIH (Grant No. AI-45194), European Commission (EC Contract IC18-CT98-0354), and Yarmouk University Research Council.

\section{REFERENCES}

AbDel-Hafez S.K., Al-Yaman F.M. \& SAID I.M. Further studies on prevalence of hydatidosis in slaughtered animals from North Jordan. Zeitschrift für Parasitenkunde, 1986, 72, 8996.

Abdel-Hafez S.K. \& Kamhawi S.A. Cystic echinococcosis in Levant countries (Jordan, Palestinian Autonomy, Israel, Syria and Lebanon), in: Compendium on Cystic Echinococcosis in Africa and in Middle Eastern Countries with Special Reference to Morocco. Andersen F.L., Ouhelli H. \& Kachani M. (eds), Brigham Young University, Provo, Utah, 1997, 292-316.

Ahmad G. \& NizAmi W.A. Coproantigens: early detection and suitability of an immunodiagnostic method for echinococcosis in dogs. Veterinary Parasitology, 1998, 77, 237244.

Ajlouni A.Q., Saliba E.K. \& Disi A.M. Intestinal cestodes of stray dogs in Jordan. Zeitschrift fur Parasitenkunde, 1984, 70, 203-210.

Allan J.C. \& Craig P.S. Coproantigens in gut tapeworm infection: Hymenolepis diminuta in rats. Parasitology Research, 1989, 76, 68-73.

allan J.C., Craig P.S., Garcia Noval J., Mencos F., Liu D., Wang Y., Wen H., Zhou P., Stinger R., Rogan M. \& Zeyhle E. Coproantigen detection for immunodiagnosis of echinococcosis and taeniasis in dogs and humans. Parasitology, 1992, 104, 347-356.
BradFord M.M. A rapid and sensitive method for the quantification of microgram quantities of protein utilizing the protein-dye binding. Analytical Biochemistry, 1976, 72, 248254 .

Craig P.S. Immunodiagnosis of Echinococcus granulosus, in: Compendium on cystic Echinococcosis with special reference to the Xinjiang Uygur autonomous region, the People's Republic of China. Andersen F.L. (ed), Brigham Young University, Provo, Utah, 1993, 85-118.

Craig P.S. Immunodiagnosis of Echinococcus granulosus and a comparison of techniques for diagnosis of canine echinococcosis, in: Compendium on cystic Echinococcosis in Africa and in Middle Eastern countries with special reference to Morocco. Andersen F.L., Ouhelli H. \& Kachani M. (eds), Brigham Young University, Provo, Utah, 1997, 85-118.

Craig P.S., Gasser R.B., Parada L., Cabrera P., Parietti S., Borgues C., Acuttis A., Agulla J., Snowden K. \& Paolillo E. Diagnosis of canine echinococcosis: comparison of coproantigen and serum antibody tests with arecoline purgation in Uruguay. Veterinary Parasitology, 1995, 56, 293301.

Deplazes P., Gottstein B., Eckert J., Jenkins D.J., Ewald D. \& Jimenez-Palacos S. Detection of Echinococcus coproantigens by enzyme-linked immunosorbent assay in dogs, dingoes and foxes. Parasitology Research, 1992, 78, 303308.

Deplazes P., Jimenez-Palacios S., Gottestein B., Skaggs J. \& ECKERT J. Detection of Echinococcus coproantigens in stray dogs of northern Spain. Applied Parasitology, 1994, 35, 297 301.

Eckert J., Gemmell M.A., Soulsby E.J.L. \& Matyas Z. Guideline for surveillance, prevention and control of Echinococcosis/Hydatidosis. World Health Organization, 1984, $147 \mathrm{p}$.

El-Shehabi F.S., Abdel-Hafez S.K. \& Kamhawi S.A. Prevalence of intestinal helminths of dogs and foxes from Jordan. Parasitology Research, 1999, 85, 928-934.

Gasser R.B., Lightowlers M.W., OBendorf D.L., Jenkins D.J. \& RICKARD M.D. Evaluation of a serological test system for the diagnosis of natural Echinococcus granulosus infection in dogs using E. granulosus protoscolex and oncospheral antigens. Australian Veterinary Journal, 1988, 65, 369-373.

Gasser R.B., Jenkins D.J., Paolillo E., Parada L., Cabrera P. \& Craig P.S. Serum antibodies in canine echinococcosis. International Journal for Parasitology, 1993, 23, 579-586.

Gemmell M.A. Quantifying the transmission dynamics of the family Taenidae with particular reference to Echinococcus spp.: an update, in: Compendium on cystic Echinococcosis in Africa and in Middle Eastern countries with special reference to Morocco. Andersen F.L., Ouhelli H. \& Kachani M. (eds), Brigham Young University, Provo, Utah, 1997, 54-71.

Jenkins D.J. \& Rickard M.D. Specific antibody responses to Taenia bydatigena, Taenia pisiformis and Echinococcus granulosus infection in dogs. Australian Veterinary Journal, 1985, 62, 72-78. 
JENKINS D.J. \& RickaRd M.D. Specific antibody responses in dogs experimentally infected with Echinococcus granulosus. American Journal of Tropical Medicine and Hygiene, 1986, 35, 345-349.

Malgor R., Nonaka N., Basmadjian I., Sakai H., Carambula B., Oku Y., Carmona C. \& Kamiya M. Coproantigen detection in dogs experimentally and naturally infected with Echinococcus granulosus by a monoclonal antibody-based enzyme-linked immunosorbent assay. International Journal for Parasitology, 1997, 27, 1605-1612.

Matossian R.M., RickaRD M.D. \& SMYTH J.D. Hydatidosis: a global problem of increasing importance. Bulletin of World Health Organization, 1977, 55, 499-507.

Nonaka N., Iida M., Yagi K., Ito T., OOI H.K., OKu Y. \& KamiYA M. Time course of coproantigen excretion in Echinococcus multilocularis infections in foxes and alternative definitive host, golden hamsters. International Journal for Parasitology, 1996, 26, 1271-1278.

Schantz P.M., Chai J., Craig P.S., Eckert J., Jenkins D.J., MaCPHERSON C.N.L. \& THAKUR A. Epidemiology and control of hydatid disease, in: Echinococcus and hydatid disease. Thompson R.C.A. \& Lymbery A.J. (eds), CAB International, Wallingford, 1995, 233-331.

SCHANTZ P.M.\& Kramer M.H.J. Larval cestode infections: cysticercosis and echinococcosis. Current Opinions in Infectious Diseases, 1995, 8, 342-350.

Schantz P.M. Sources and uses of surveillance data for cystic echinococcosis, in: Compendium on cystic Echinococcosis in Africa and in Middle Eastern countries with special reference to Morocco. Andersen F.L., Ouhelli H. \& Kachani M. (eds), Brigham Young University, Provo, Utah, 1997, 72-84.

Reçu le 7 octobre 1999

Accepté le 14 mars 2000 